\title{
Acceptability and perceived effectiveness of a single-session mindfulness intervention for medical residents
}

\author{
D. Carsley ${ }^{1}$, I. Sadowski ${ }^{1}$, N. L. Heath ${ }^{1}$, R. Montoro ${ }^{2}$ \&. S. Miller ${ }^{3}$
}

\begin{abstract}
Introduction: Medical residents report high levels of stress, with many work-related demands contributing to their experience of heightened stress. Mindfulness training has been suggested as a beneficial strategy for stress management with residents; however, many mindfulness programs are time-consuming, and compliance with conventional mindfulness training programs becomes challenging given the intense, competing time commitments of residency. The present study sought to evaluate the acceptability and perceived effectiveness of a single-session, mindfulness-based stress management workshop for medical residents.
\end{abstract}

Methods: Residents $(\mathrm{n}=142)$ from family medicine, internal medicine and general surgical residency programs participated in a 1.5-hour mindfulness workshop in 2016 and completed: a measure of workshop satisfaction immediately post-workshop; a measure of adherence to suggested strategies $4-6$ weeks post-workshop; and measures of stress, mindfulness and positive and negative affect immediately post-workshop and 4-6 weeks post-workshop.

Results: Results revealed high levels of satisfaction with the workshop. Participants who used the recommended strategies over the 4 to 6-week post-workshop period reported significant increases in mindfulness and significant decreases in stress at follow-up.

Conclusions: Results suggest single-session mindfulness training can be beneficial for residents who use the strategies effectively; however, ensuring strategy use following training is challenging. Future research is needed to investigate facilitators and barriers to strategy use.

Department of Educational and Counselling Psychology, McGill University, Montreal, Quebec, Canada

Montreal General Hospital Department of Psychiatry, McGill University Health Centre, Montreal, Quebec, Canada

3 The Law School, University of Notre Dame, Notre Dame, Indiana, United States

\section{Correspondence}

Dana Carsley

Department of Educational and Counselling Psychology

McGill University

3700 McTavish Street

Montreal, QC, H3A 1 Y2

Canada

Tel: +1 5143981232

Email: dana.carsley@mcgill.ca 
Keywords: medical residents; mindfulness; stress management; medical education; resilience

\section{Introduction}

Medical residents are reporting high levels of stress, with work-related demands contributing to this experienced stress (Anagnostopoulos et al., 2015; Dyrbye \& Shanafelt, 2016; Dyrbye et al., 2014; National Physician Survey, 2012; Prins, GazendamDonofrio, et al., 2007). Time pressure, an increasingly heavy workload, organisational and planning requirements and challenges with work-life balance are among the many factors influencing this experienced stress (Anagnostopoulos et al., 2015). Compared to physicians and non-practitioners, stress experienced during residency training is associated with higher levels of burnout (Bellini et al., 2002; Lemkau et al., 1988; McCue \& Sachs, 1991; Prins, Gazendam-Donofrio, et al., 2007; Ripp et al., 2010), and both stress and burnout peak during the first years of resident training (Martini et al., 2004; Nguyen et al., 2020; Shanafelt et al., 2002).

Residents' experienced stress has been shown to be related to other negative outcomes, such as decreased empathy for patients (Bellini et al., 2002; Bellini \& Shea, 2005; Mangione et al., 2002) and a decrease in patient safety (e.g., late timing of patient discharge, limited attention and time for patients) (Anagnostopoulos et al., 2015; Prins, van der Heijden, et al., 2009). If residents are unable to manage and treat their stress, they are at risk for mental health problems (Bellini et al., 2002; Eckleberry-Hunt et al., 2009; Wang et al., 2010), which can also lead to medical errors (Fahrenkopf et al., 2008; West et al., 2006). To limit the overwhelming stress residents experience and the associated negative outcomes, it is critical to find methods to limit residents' stress and support their wellbeing, in addition to their patients' wellbeing.

Recently, mindfulness, a nonjudgmental focused awareness and acceptance of the present moment (Kabat-Zinn, 2003), has been shown to be a helpful strategy and intervention to manage medical residents' stress and has been recommended for ensuring residents', nurses' and other medical faculties' successful job performance (Real et al., 2017). In particular, mindfulness-based stress reduction (MBSR), which consists of an 8-week group intervention that emphasises the enhancement of mindfulness skills through mindfulness meditation exercises and rehearsal (Burke, 2010), is one of the most accepted mindfulness approaches to managing stress in an array of populations (Bazarko et al., 2013; Fjorback et al., 2011). Mindfulness practices have been shown to increase awareness and enhance interpersonal skills (Epstein, 1999; Polack et al., 2010; Raper et al., 2014), as well as improve empathy (Polack et al., 2010), which are essential for a patient-centered profession such as medicine.

In a recent study on mindfulness in medical residents, Real and colleagues (2017) examined relations between mindfulness and performance in 51 residents working in an intensive care unit (Real et al., 2017). Results revealed significant positive correlations between performance and mindfulness, positive affect and communication, as reported by residents, as well as a positive relationship between mindfulness and communication, and a negative relationship between mindfulness and negative affect, 
as perceived by physicians and registered nurses. These results demonstrate that the ability to be mindful can have an impact on the quality of patient care. A number of mindfulness programs for individuals working in health professions (e.g., medical students, physicians) have been created and examined; however, there have only been a few recent studies specifically focusing on mindfulness programs for residents (e.g., Cavanaugh \& Rose, 2017; Ireland et al., 2017; Lases et al., 2016). Although these studies provide preliminary evidence for the effectiveness of a mindfulness intervention for medical residents' stress, anxiety and burnout reduction, these programs consisted of several sessions over a 2 to 3 -month period. Given the limited time and various work demands experienced by residents, it would be helpful to assess if residents experience similar benefits in a brief single-session mindfulness program.

Prasad and colleagues (2011) evaluated the effect of a single-session meditation program for health clinic employees on stress, anxiety and quality of life. Although the session was not delivered to residents, these participants worked in an academic medical centre and were exposed to many stressful situations, similar to medical residents. Seventeen participants attended a 2-hour training session and then practised mindfulness for 5-30 minutes over a period of 4 weeks. Results revealed significant improvements in perceived stress, anxiety and overall quality of life. As such, it would be important to assess these benefits with a single-session workshop in a population of residents, who are at risk for extreme stress and burnout.

In Dobkin and Hutchinson's (2013) review, mindfulness was being taught in a variety of formats to medical and dental students and residents in 14 medical schools; however, the programs of shorter length reviewed in this article were targeted towards medical students. Overall, results from these programs revealed reductions in stress and negative emotions, as well as increases in mindfulness. The authors noted that the positive outcomes did not vary according to the way the programs were taught (e.g., length, mandatory/elective course, etc.); therefore, it is conceivable that residents may not require lengthy mindfulness programs to experience the associated benefits. Given that the brief programs were targeted towards medical students, the overarching objective of the present study was to evaluate the acceptability and effectiveness of a single-session mindfulness-based stress management workshop for medical residents. Specific objectives were to examine (a) participant satisfaction with a single-session mindfulness for stress management workshop, (b) the rate of participant adherence to suggested practice guidelines during the 4-6 week follow-up period and (c) changes in reports of perceived experienced stress, mindfulness and positive and negative affect following the workshop.

\section{Methods}

All data collection involving human subjects was in accordance with the ethical standards of the university and Canada's Tri-Council Research Ethics Guidelines (REB File \#: 283-1215). The research study was undertaken between February and April 2016. Please refer to Figure 1 for a flowchart detailing the study procedure. 


\section{Figure 1}

Flow Diagram of Study Procedure

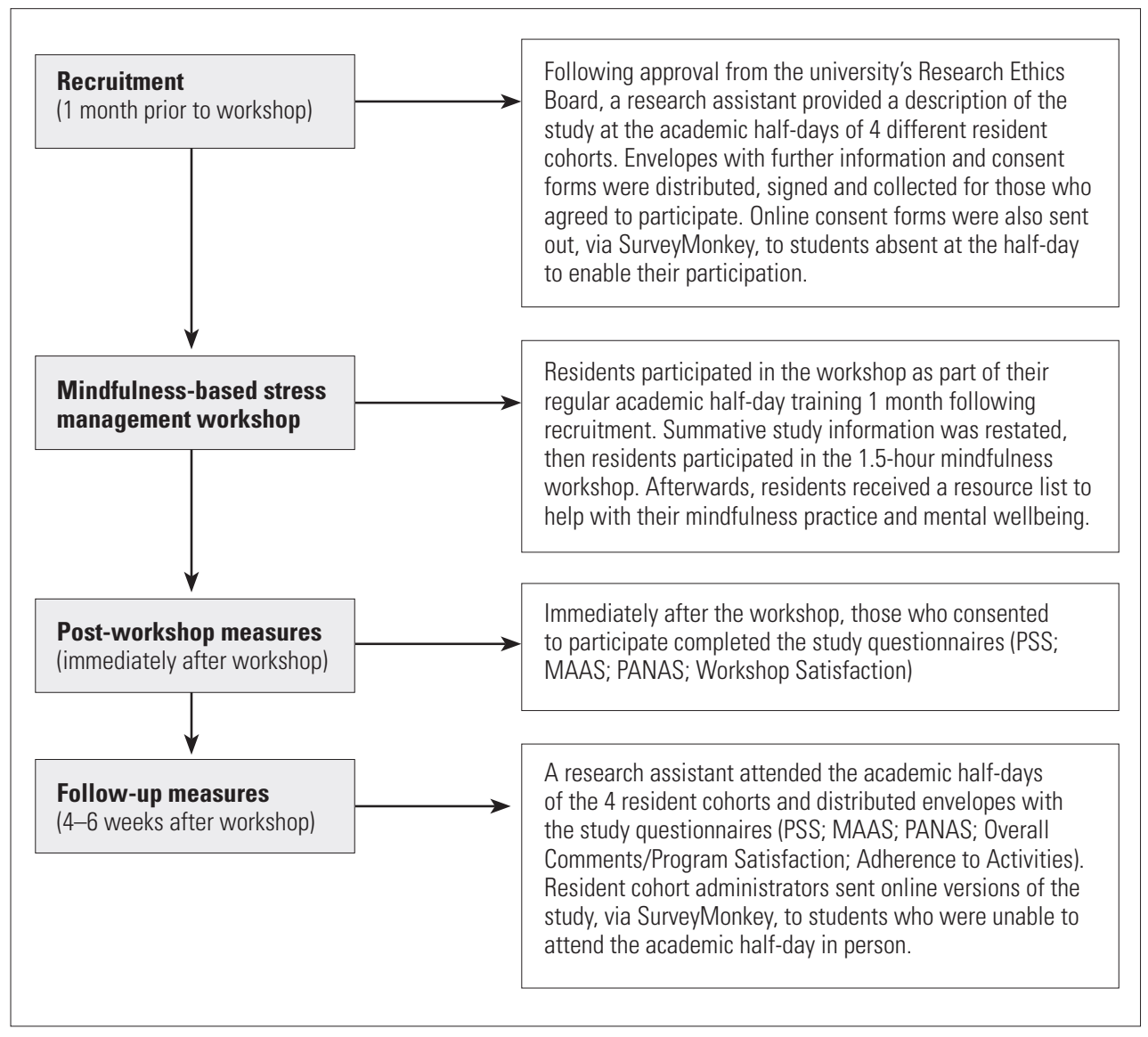

\section{Participants}

The study sample consisted of 142 medical residents ( $47.5 \%$ female) from a university in Montreal, Quebec, Canada. Medical residency specialties included family medicine $(\mathrm{n}=70 ; 49.3 \%)$, internal medicine $(\mathrm{n}=40 ; 28.2 \%)$ and surgery $(\mathrm{n}=32 ; 22.5 \%)$. Participants' ages ranged from 22 to 40 years $(M=27.9, S D=3.8)$.

\section{Program summary}

The single-session 1.5-hour mindfulness-based stress management workshop for medical residents aimed to equip residents with the appropriate techniques to effectively cope with their highly stressful environments. Within their training/residency, participants had not undertaken a similar session in this area. The development of the workshop content was guided by a detailed review of the literature, as well as clinical 
expertise. The 1.5-hour long program consisted of the following eight components: (1) introduction, (2) relevance of mindfulness for medical residents, (3) defining and describing mindfulness, (4) discussion of research results regarding the effectiveness and mechanisms underlying the effectiveness of mindfulness, (5) discussion of potential obstacles and solutions in using mindfulness, (6) outlining recommended mindfulness activities (i.e., "3 good things", mindful eating and body scan), (7) practising these activities (throughout the 1.5 hours) and (8) closing remarks on the continued use of the activities and next steps in research. The workshop was delivered by a medical education wellness counsellor.

\section{Measures}

Immediately after the workshop, those who consented to participate in the research study completed measures of perceived stress, mindfulness, positive and negative affect as well as workshop satisfaction. At follow-up 4-6 weeks after the workshop, participants were asked to complete measures of perceived stress, mindfulness, positive and negative affect, adherence to activities and overall comments/program satisfaction (detailed below).

\section{Demographics questionnaire}

Information gathered included participant gender, age, ethnicity, languages spoken and educational history.

\section{Perceived stress}

The Perceived Stress Scale (PSS; Cohen et al., 1983) is a widely used self-report measure in which participants indicate their experience of stress and the degree to which life situations are stressful on a 5 -point scale $(0=$ never, $4=$ very often $)$. To assess change in experienced stress following the workshop, statements were adapted from "in the last month" to "in the last week". In the current study, Cronbach alphas ranged from .929 to .934 .

\section{Mindfulness}

The Mindful Attention Awareness Scale (MAAS; Brown \& Ryan, 2003) measures dispositional mindfulness through focusing on the absence of mindful attention and awareness. Participants rate their responses to 15 items on a 6-point scale $(1=$ almost always; $6=$ almost never). Statements were adapted from present to past tense to reflect participants' dispositional mindfulness "in the past week". In the present study, Cronbach alphas ranged from .933 to .947 .

\section{Positive and negative affect}

The Positive and Negative Affect Schedule (PANAS) is a widely used self-report measure of affective states in adults (Huebner \& Dew, 1995; Tuccitto et al., 2010; Watson et al., 1998), consisting of two 10-item mood scales that assess individuals levels of positive and negative affect. Participants report their experiencing of these emotions on a 5 -point scale $(1=$ very slightly or not at all; $5=$ extremely $)$ according to the specific 
time frame indicated in the questionnaire (e.g., right now, in general, past week, etc.). In the present study, statements corresponded to the "past week" and Cronbach alphas ranged from .731 to .738 .

\section{Workshop satisfaction}

Immediately post-workshop, this researcher-developed questionnaire asked participants to rate if the workshop (1) was a valuable professional/personal development experience, (2) was recommendable to their colleagues, (3) provided important information on mindfulness for stress management, (4) improved confidence in their understanding of the suggested techniques and (5) included techniques that they intended to try in the following weeks. All items used a 5-point Likert-style scale ranging from "strongly agree" to "strongly disagree".

\section{Adherence to activities}

During the follow-up session, participants were also asked to indicate how frequently they engaged in the taught mindfulness techniques since participating in the program, and to specify which techniques they used. Frequency was assessed using a 4-point rating scale $(1=$ never; $4=$ every day $)$. Participants who indicated that they practised mindfulness techniques were asked if and why they found the techniques to be helpful. Space was provided for residents to offer general comments on the program.

\section{Overall comments/program satisfaction}

This researcher-developed questionnaire, administered at follow-up, assessed the same aspects of participant satisfaction and knowledge as the "workshop satisfaction" questionnaire. One section assessed self-reported participant change in behavior, measuring whether participants had used the strategies they learned in the workshop and whether they planned to continue using them. All items used a 5-point Likert-style scale ranging from "strongly agree" to "strongly disagree".

\section{Data analysis}

All data were analysed using IBM SPSS Statistics for Windows, Version 20.0 (IBM Corp, Armonk, New York). Participant satisfaction was assessed by calculating the percentage of participant agreement for each item. A series of repeated measures ANOVAs were conducted to test the effectiveness of the workshop on mindfulness, stress and positive and negative affect from post-workshop to follow-up.

\section{Results}

Of the 142 residents who consented to participate in the workshop, 106 participants completed the post-workshop measures, and 51 of these completed follow-up measures. $\left(\mathrm{n}=51 ; 53.3 \%\right.$ female; $M_{\text {age }}=28.55$ years, $\left.S D=4.21\right)$. In the dataset, a total of 16 missing values were found. An examination of this missing data revealed that all variables had less than $5 \%$ of missing values. Given that the data is considered to be missing completely at random, the expectation maximisation procedure was used to 
impute the missing data. Reasons for attrition or non-completion of measures included absenteeism (i.e., residents were scheduled to be elsewhere during the class) and classroom interruptions (e.g., residents were on-call).

\section{Satisfaction with a brief mindfulness workshop for medical residents}

Immediately post-workshop, $73.6 \%(n=78)$ of participants agreed $(n=63 ; 59.4 \%)$ or strongly agreed $(\mathrm{n}=15 ; 14.2 \%)$ that this workshop was a valuable professional/personal development experience for them; 69.6\% $(n=74)$ of participants agreed $(n=59$; $55.7 \%)$ or strongly agreed $(\mathrm{n}=15 ; 14.2 \%)$ that they would recommend this workshop to other colleagues; and $77.4 \%(n=82)$ of participants agreed $(n=62 ; 58.5 \%)$ or strongly agreed $(n=20 ; 18.9 \%)$ that this workshop provided useful information on mindfulness for stress management. Furthermore, 77.4\% $(\mathrm{n}=82)$ of participants agreed $(n=67 ; 63.2 \%)$ or strongly agreed $(n=15 ; 14.2 \%)$ that they felt confident in their understanding of the suggested techniques that were taught; and $77.4 \%$ $(n=82)$ of participants agreed $(n=64 ; 60.4 \%)$ or strongly agreed $(n=18 ; 17 \%)$ that they planned to try these techniques over the coming weeks.

\section{Satisfaction with program and changes in behavior 4 to 6 weeks following the workshop}

At follow-up, $60.4 \%(n=29)$ of participants agreed $(n=22 ; 45.8 \%)$ or strongly agreed $(\mathrm{n}=9 ; 14.6 \%)$ that the program was a valuable professional/personal development experience for them; $64.6 \%(n=31)$ of participants agreed $(n=23 ; 47.9 \%)$ or strongly agreed $(\mathrm{n}=8 ; 16.7 \%)$ that they would recommend this training to other colleagues; and $47.9 \%(n=23)$ of participants agreed $(n=18 ; 37.5 \%)$ or strongly agreed $(n=5$; $10.4 \%$ ) that they learned important information about using mindfulness for stress management.

At follow-up, 29.2\% ( $\mathrm{n}=14)$ of participants agreed $(\mathrm{n}=11 ; 22.9 \%)$ or strongly agreed $(\mathrm{n}=3 ; 6.3 \%)$ that they used the strategies they learned in the workshop and $45.8 \%$ $(n=22)$ of participants agreed $(n=17 ; 35.4 \%)$ or strongly agreed $(n=5 ; 10.4 \%)$ that they planned to continue or commence using these techniques. Reported adherence to specific activities is included in Table 1.

\section{Table 1}

Percentage of Participants' Adherence to Activities 4 to 6 Weeks Following the Mindfulness Workshop

\begin{tabular}{l|c|c|c|c}
\hline & $\begin{array}{c}\text { 3 Good Things } \\
(\mathrm{n}=48)\end{array}$ & $\begin{array}{c}\text { Mindful Eating } \\
(\mathrm{n}=48)\end{array}$ & $\begin{array}{c}\text { Body Scan } \\
(\mathrm{n}=49)\end{array}$ & $\begin{array}{c}\text { Other Mindful } \\
\text { Practices }(\mathrm{n}=45)\end{array}$ \\
\hline Never & 60.4 & 60.4 & 61.2 & 71.1 \\
\hline Occasionally & 25.0 & 27.1 & 24.5 & 17.8 \\
\hline Frequently & 10.4 & 10.4 & 12.2 & 8.9 \\
\hline Every day & 4.2 & 2.1 & 2.0 & 2.2 \\
\hline
\end{tabular}




\section{Changes in mindfulness, stress and affect 4 to 6 weeks following the workshop}

Repeated measures ANOVAs for participants ( $\mathrm{n}=51)$ were conducted to test the effectiveness of the workshop on mindfulness, stress and positive and negative affect from post-workshop to follow-up at 4 to 6 weeks. Results revealed a significant increase in mindfulness 4 to 6 weeks post-workshop $(F(1,50)=4.26, p<.05$, Wilk's $\Lambda=.922$, partial $\left.\eta^{2}=.078\right)$ with a mean of $3.74(S D=1.08)$ post-workshop and $4.00(S D=1.01)$ at follow-up, and a significant decrease in stress 4 to 6 weeks post-workshop $(F(1,50)$ $=4.04, p<.05$, Wilk's $\Lambda=.910$, partial $\left.\eta^{2}=.081\right)$ with a mean of $16.96(S D=7.98)$ post-workshop and $14.98(S D=7.2)$ at follow-up; however, participants' positive affect (PA) and negative affect (NA) were not significantly different at follow-up (PA: $F(1,49)$ $=.078, p=.781$; NA: $F(1,49)=.912, p=.344)$.

To determine the effect on mindfulness and stress specifically for participants who reported that they used the strategies learned in the workshop $(\mathrm{n}=15)$, repeated measures ANOVAs were conducted. Results revealed a significant increase in mindfulness $(F(1$, $13)=7.19, p<.05$, Wilk's $\Lambda=.644$, partial $\left.\eta^{2}=.356\right)$ and a significant decrease in stress at follow-up $\left(F(1,13)=7.41, p<.05\right.$, Wilk's $\Lambda=.637$, partial $\eta^{2}=.363$ ) (see Table $2)$. No significant differences for positive affect $(F(1,12)=.583, p=.460)$ or negative affect $(F(1,12)=1.83, p=.201)$ were found. Participants who indicated that they did not use the strategies did not show any change in mindfulness $(F(1,18)=.094, p=.762$, stress $F(1,18)=.199, p=.661)$, positive affect $(F(1,18)=.286, p=.599)$ or negative affect $(F(1,18)=.615, p=.443)$ at follow-up.

\section{Table 2}

Means (and Standard Deviations) for Mindfulness and Stress for Participants Indicating Continued Use of Strategies Learned in Workshop at 4 to 6-Week Follow-Up

\begin{tabular}{l|c|c|c|c}
\hline & $\begin{array}{c}\text { Mindfulness } \\
\text { (Pre) }\end{array}$ & $\begin{array}{c}\text { Mindfulness } \\
\text { (Post) }\end{array}$ & $\begin{array}{c}\text { Stress } \\
\text { (Pre) }\end{array}$ & $\begin{array}{c}\text { Stress } \\
\text { (Post) }\end{array}$ \\
\hline $\mathrm{n}$ & $M(S D)$ & $M(S D)$ & $M(S D)$ & $M(S D)$ \\
\hline 14 & $3.26(1.08)$ & $3.92(1.11)$ & $20.64(8.49)$ & $16(7.2)$ \\
\hline
\end{tabular}

The expectation maximisation procedure was used in this study to maintain the sample size given the rate of attrition at follow-up. To verify the findings, analyses for the effects of mindfulness were conducted without the imputed data. The findings did not differ except for the slight diminishing of significance of the change in mindfulness overall, which was now approaching significance $(\mathrm{F}(1,43)=3.4, p=.072)$. Participants who indicated that they used the strategies reported a significant increase in mindfulness at follow-up $\left(F(1,11)=6.70, p<.05\right.$, Wilk's $\Lambda=.621$, partial $\left.\eta^{2}=.379\right)$, and participants who indicated that they did not use the strategies did not show any change in mindfulness at follow-up $(F(1,15)=.004, p=.949)$. 


\section{Discussion}

The purpose of this study was to evaluate the acceptability and perceived effectiveness of a brief mindfulness-based stress management workshop for medical residents. Specific objectives were to assess (a) participant satisfaction with a single-session mindfulness for stress management workshop, (b) the rate of participant adherence to suggested practice guidelines during the 4-6 week follow-up period and (c) changes in reports of perceived experienced stress, mindfulness and positive and negative affect following the workshop.

Immediately post-workshop, and 4-6 weeks post-workshop, residents indicated that the mindfulness workshop was a valuable professional development experience and they would recommend it to their colleagues. Residents were confident in their understanding of the mindfulness techniques taught during the workshop, and the majority of residents indicated that they planned to practise these techniques. Based on anecdotal evidence, it was expected that residents might be resistant to the content and time commitment of the program; however, this shorter, relevant program was well-received by residents. Many of the mindfulness-based programs for individuals working in health professions can be lengthy and time-consuming (Cavanaugh et al., 2017; Ireland et al., 2017; Lases et al., 2016). These results suggest that a single-session workshop can be perceived as helpful by residents, which is particularly important given the work and time demands of this profession.

At follow-up, about one third of residents indicated that they practised the mindfulness techniques; however, almost half of the residents indicated that they still planned to practise the mindfulness strategies going forward. Several explanations might account for these findings. First, residents experience competing demands for attention and are continuously learning and developing skills as part of their training; therefore, they may have had limited time, energy or motivation to invest in a non-evaluated skill in favor of skills that were being assessed. In mindfulness training, in general, participants may experience challenges committing to practising the techniques. One method that is particularly effective at improving adherence is having a community context for practice, led by a teacher trained in mindfulness techniques (Dimidjian \& Linehan, 2003). As such, future research could evaluate whether including a 5-minute mindfulness practice led by a faculty or clinical supervisor would be helpful in improving residents' adherence. Furthermore, the incorporation of mindful moments into the curriculum and possibly the creation of multiple mindful spaces might help facilitate strategy use post-workshop. Further studies are required to assess barriers to strategy use following the initial workshop.

Consistent with the literature, the sample of residents in this study showed high levels of stress (Dyrbye \& Shanafelt, 2016), which further confirms the need for training in strategies to manage stress in this group. At 4-6 weeks post-workshop, participants reported an overall significant increase in mindfulness and decrease in stress; however, closer examination of the findings revealed that this was only significant for participants who indicated that they used the recommended strategies. These findings are consistent with previous literature showing that residents who practised mindfulness skills 
taught during training showed significant decreases in perceived stress and increases in mindfulness (Cavanaugh \& Rose, 2017; Ireland et al., 2017; Lases et al., 2016); however, these previously conducted studies were lengthier, more time-consuming and required more resources, unlike the current study that shows how single-session mindfulness training can be as effective. Medical residency programs should consider incorporating brief mindfulness-based stress management workshops into their training programs to support students and provide them with opportunities to enhance their personal wellbeing, potentially positively influencing their ability to perform in their professional environment (Ratanawongsa et al., 2008).

Participants' levels of positive and negative emotions experienced did not significantly change, regardless of whether they practised the skills taught in the workshop. These findings are inconsistent with previous research evaluating the effectiveness of wellness training in residents, which suggests a positive relationship between mindfulness and positive emotions (Real et al., 2017); however, research on the emotional experience of residents throughout the internship year indicates that positive emotions tend to decrease and negative emotions tend to increase, possibly due to this stressful period, which includes sleep deprivation, long hours and challenging patients (Bellini et al., 2002). Given that the present study followed a similar timeline, a finding indicating no change in emotion may in fact be indicative of an improvement, or of the potential coping role that mindfulness played on residents' perceptions of stress in the face of experienced negative emotions.

Another potential reason for the absence of increases in positive emotions could be that the current workshop focused on skills particularly targeted towards mindfulness and stress management, as opposed to the experiencing of positive emotions. In the future, mindfulness-based workshops could include more information related to increasing positive emotions, in addition to stress management, to assess changes in this area. Additionally, a longer follow-up period may be helpful to identify whether positive emotions increase over time. A study by Fredrickson and colleagues (2008) found that practising loving-kindness meditation (a type of mindfulness-meditation training focusing specifically on the cultivation of warm and positive emotions) increased the frequency with which participants experienced positive emotions cumulatively over time. However, the participants in the Fredrickson et al. study were a general community sample of working adults rather than those working in a high-pressure profession with competing demands. Further research examining the effect of time in increasing positive emotions of medical residents following mindfulness training is warranted.

Despite these findings, this study was not without limitations. Primarily, 4-6 weeks post-workshop, attrition rates were high, which resulted in a small sample size and an inability to assess the benefits between the different types of resident groups (e.g., family medicine vs. internal medicine). Although high attrition is common for medical residents, future studies could consider offering significant compensation to encourage participants to complete follow-up measures online in the event that faceto-face completion is not possible due to scheduling difficulties. Secondly, although 
we attempted to conduct a comparison by ethnicity, the statistical power was so low (.105-.468) that a comparison was not possible. Future research would benefit from assessing the correlation between ethnicity and/or culture and mindfulness to develop a better understanding of the relationship. Thirdly, although this study included a prepost design, a control group was not possible as the mindfulness workshop was given as part of the regular residency curriculum. It was not feasible to conduct the study outside of the regular program given the residents' competing demands, limited availability and time constraints. Finally, the data was collected through self-report measures, which is a limitation in intervention research (e.g., response bias); nevertheless, given that the study was not facilitated or conducted by the residents' supervisors and the fact that all material was confidential and distributed and collected by research assistants, power differentials was not a concern, and it was unlikely that the residents had reason to inflate their satisfaction ratings or reports of strategy adherence.

\section{Conclusion}

This study revealed that a brief mindfulness workshop for residents can be regarded as highly satisfactory for residents; however, the actual effectiveness of the workshop requires participant adherence of strategies. Although participants' positive and negative affect did not significantly change post-workshop, a significant decrease in stress and a significant increase in mindfulness were found for those who practised the techniques following the workshop. Given the high levels of stress experienced by medical residents, these findings demonstrate the potential for this single-session mindfulness stress-reduction workshop to effectively facilitate a reduction in residents' stress. Overall, these results provide preliminary support for the effectiveness of a brief mindfulness workshop for residents and demonstrate the need to increase strategy use in this particular setting so all residents can benefit. Future studies that incorporate a control group and multiple follow-up time points are warranted to better assess effectiveness and long-term outcomes. Additionally, further study of factors that may facilitate strategy use is needed.

\section{Funding and conflict of interest statement}

The authors received no specific funding for this work and declare no conflicts of interest.

\section{References}

Anagnostopoulos, F., Demerouti, E., Sykioti, O., Niakas, D., \& Zis, P. (2015).

Factors associated with mental health status of medical residents: A model-guided study. Journal of Clinical Psychology in Medical Settings, 22(1), 90-109. https://doi. org/10.1007/s10880-014-9415-2

Bazarko, D., Cate, R. A., Azocar, F., \& Kreitzer, M. J. (2013). The impact of an innovative mindfulness-based stress reduction program on the health and wellbeing of nurses employed in a corporate setting. Journal of Workplace Behavioral Health, 28(2), 107-133. https://doi.org/10.1080/15555240.2013.779518 
Bellini, L. M., Baime, M., \&. Shea, J. A. (2002). Variation of mood and empathy during internship. JAMA, 287(23), 3143-3146. https://doi.org/10.1001/ jama.287.23.3143

Bellini, L. M., \& Shea, J. A. (2005). Mood change and empathy decline persist during three years of internal medicine training. Academic Medicine, 80(2),164167. https://doi.org/10.1097/00001888-200502000-00013

Brown, K., \& Ryan, R. (2003). The benefits of being present: Mindfulness and its role in psychological wellbeing. Journal of Personality and Social Psychology, 84(4), 822-848. https://doi.org/10.1037/0022-3514.84.4.822

Burke, C. A. (2010). Mindfulness-based approaches with children and adolescents: A preliminary review of current research in an emergent field. Journal of Child and Family Studies, 19(2), 133-144. https://doi.org/10.1007/s10826-009-9282-x

Cavanaugh, E., \& Rose, M. (2017). An 8-week mindfulness-based stress reduction course for ob/gyn residents: A pilot study. Obstetrics \& Gynecology, 130, 45S. https://doi.org/10.1097/01.AOG.0000525734.33435.0b

Cohen, S., Kamarck, T., \& Mermelstein, R. (1983). A global measure of perceived stress. Journal of Health and Social Behavior, 24(4), 385-396. https://doi. org/10.2307/2136404

Dimidjian, S., \& Linehan, M. M. (2003). Defining an agenda for future research on the clinical application of mindfulness practice. Clinical Psychology: Science and Practice, 10(2), 166-171. https://doi.org/10.1093/clipsy.bpg019

Dobkin, P. L., \& Hutchinson, T. A. (2013). Teaching mindfulness in medical school: Where are we now and where are we going? Medical Education, 47(8), 768-779. https://doi.org/10.1111/medu.12200

Dyrbye, L., \& Shanafelt, T. (2016). A narrative review on burnout experienced by medical students and residents. Medical Education, 50(1), 132-149. https://doi. org/10.1111/medu.12927

Dyrbye, L. N., West, C. P., Satele, D., Boone, S., Tan, L., Sloan, J., \& Shanafelt, T. D. (2014). Burnout among U.S. medical students, residents, and early career physicians relative to the general U.S. population. Academic Medicine, 89(3), 443-451. https://doi.org/10.1097/ACM.0000000000000134

Eckleberry-Hunt, J., Lick, D., Boura, J., Hunt, R., Balasubramaniam, M., Mulhem, E., \& Fisher, C. (2009). An exploratory study of resident burnout and wellness. Academic Medicine, 84(2), 269-277. https://doi.org/10.1097/ ACM.0b013e3181938a45

Epstein, R. M. (1999). Mindful practice. JAMA, 282(9), 833-839. https://doi. org/10.1001/jama.282.9.833

Fahrenkopf, A. M., Sectish, T. C., Barger, L. K., Sharek, P. J., Lewin, D., Chiang, V. W., Edwards, S., Wiedermann, B. L., \& Landrigan, C. P. (2008). Rates of medication errors among depressed and burnt out residents: Prospective cohort study. BMJ, 336(7642), 488-491. https://doi.org/10.1136/bmj.39469.763218. BE 
Fjorback, L. O., Arendt, M., Ørnbøl, E., Fink, P., \& Walach, H. (2011). Mindfulness-based stress reduction and mindfulness-based cognitive therapy: A systematic review of randomized controlled trials. Acta Psychiatrica Scandinavica, 124(2), 102-119. https://doi.org/10.1111/j.1600-0447.2011.01704.x

Fredrickson, B. L., Cohn, M. A., Coffey, K. A., Pek, J., \& Finkel, S. M. (2008). Open hearts build lives: Positive emotions, induced through loving-kindness meditation, build consequential personal resources. Journal of Personality and Social Psychology, 95(5), 1045-1062. https://doi.org/10.1037/a0013262

Huebner, E. S., \& Dew, T. (1995). Preliminary validation of the positive and negative affect schedule with adolescents. Journal of Psychoeducational Assessment, 13(3), 286-293. https://doi.org/10.1177/073428299501300307

Ireland M. J., Clough, B., Gill, K., Langan, F., O'Connor, A., \& Spencer, L. (2017). A randomized controlled trial of mindfulness to reduce stress and burnout among intern medical practitioners. Medical Teacher, 39(4), 409-414. https://doi.org/10. 1080/0142159X.2017.1294749

Kabat-Zinn, J. (2003). Mindfulness-based interventions in context: Past, present, and future. Clinical Psychology: Science and Practice, 10(2), 144-156. https://doi. org/10.1093/clipsy/bpg016

Lases, S. S., Lombarts, M. J. M. H., Slootweg, I. A., Arah, O. A., Pierik, E. G. J. M., $\&$ Heineman, E. (2016). Evaluating mind fitness training and its potential effects on surgical residents' well-being: A mixed methods pilot study. World Journal of Surgery, 4O(1), 29-37. https://doi.org/10.1007/s00268-015-3278-z

Lemkau, J. P., Purdy, R. R., Rafferty, J. P., \& Rudisill, J. R. (1988). Correlates of burnout among family practice residents. Journal of Medical Education, 63(9), 682-691. https://doi.org/10.1097/00001888-198809000-00003

Mangione, S., Kane, G. C., Caruso, J. W., Gonnella, J. S., Nasca, T. J., \& Hojat, M. (2002). Assessment of empathy in different years of internal medicine training. Medical Teacher, 24(4), 370-373. https://doi.org/10.1080/01421590220145725

Martini, S., Arfken, C. L., Churchill, A., \& Balon, R. (2004). Burnout comparison among residents in different medical specialties. Academic Psychiatry, 28(3), 240-242. https://doi.org/10.1176/appi.ap.28.3.240

McCue, J. D., \& Sachs, C. L. (1991). A stress management workshop improves residents' coping skills. Archives of Internal Medicine, 151(11), 2273-2277. https://doi.org/10.1001/archinte.1991.00400110117023

National Physician Survey. (2012). 2012 national physician survey. http://nationalphysiciansurvey.ca/surveys/2012-survey/

Nguyen, M. C., Gabbe, S. G., Kemper, K. J., Mahan, J. D., Cheavens, J. S., \& Moffatt-Bruce, S. D. (2020). Training on mind-body skills: Feasibility and effects on physician mindfulness, compassion, and associated effects on stress, burnout, and clinical outcomes. The Journal of Positive Psychology, 15(2), 194-207. https://doi.org/10.1080/17439760.2019.1578892 
Polack, E. P., Avtgis, T. A., Rossi, D. C., \& Shaffer, L. (2010). A team approach in communication instruction: A qualitative description. Journal of Surgical Education, 67(3), 125-128. https://doi.org/10.1016/j.jsurg.2010.02.004

Prasad, K., Wahner-Roedler, D., Cha, S. S., \& Sood, A. (2011). Effect of a singlesession meditation training to reduce stress and improve quality of life among health care professionals: A "dose-ranging" feasibility study. Alternative Therapies, 17(3), 46-49.

Prins J. T., Gazendam-Donofrio S. M., Tubben B. J., van der Heijden F. M. M. A., van de Wiel H. B. M., \& Hoekstra-Weebers J. E. H. M. (2007). Burnout in medical residents: A review. Medical Education, 41(8), 788-800. https://doi. org/10.1111/j.1365-2923.2007.02797.x

Prins, J. T., van der Heijden, F. M., Hoekstra-Weebers, J. E. H. M., Bakker, A. B., van de Wiel, H. B. M., Jacobs, B., \& Gazemdam-Donofrio, S. M. (2009). Burnout, engagement and resident physicians' self-reported errors. Psychology, Health \& Medicine, 14(6), 654-666. https://doi.org/10.1080/13548500903311554

Raper, S. E., Resnick, A. S., \& Morris, J. B. (2014). Simulated disclosure of a medical error by residents: Development of a course in specific communication skills. Journal of Surgical Education, 71(6), e116-e126. https://doi.org/10.1016/j. jsurg.2014.06.020

Ratanawongsa, N., Wright, S. M., \& Carrese, J. A. (2008). Well-being in residency: Effects on relationships with patients, interactions with colleagues, performance, and motivation. Patient Education and Counseling, 72(2), 194-200. https://doi. org/10.1016/j.pec.2008.04.010

Real, K., Fields-Elswick, K., \& Bernard, A. C. (2017). Understanding resident performance, mindfulness, and communication in critical care rotations. Journal of Surgical Education, 74(3), 503-512. https://doi.org/10.1016/j.jsurg.2016.11.010

Ripp, J., Fallar, R., Babyatsky, M., David, R., Reich, L., \& Korenstein, D. (2010). Prevalence of resident burnout at the start of training. Teaching and Learning Medicine, 22(3), 172-175. https://doi.org/10.1080/10401334.2010.488194

Shanafelt, T. D., Bradley, K. A., Wipf, J. E., \& Back, A. L. (2002). Burnout and self-reported patient care in an internal medicine residency program. Annals of Internal Medicine, 136(5), 358-367. https://doi.org/10.7326/0003-4819-136-5200203050-00008

Tuccitto, D. E., Giacobbi, P. R., Jr., \& Leite, W. L. (2010). The internal structure of positive and negative affect: A confirmatory factor analysis of the PANAS. Educational and Psychological Measurement, 70(1), 125-141. https://doi. org/10.1177/0013164409344522

Wang, J.-N., Sun, W., Chi, T.-S., Wu, H., \& Wang, L. (2010). Prevalence and associated factors of depressive symptoms among Chinese doctors: A crosssectional survey. International Archives of Occupational and Environmental Health, 83(8), 905-911. https://doi.org/10.1007/s00420-010-0508-4 


\section{SINGLE-SESSION MINDFULNESS INTERVENTIONS}

Watson, D., Clark, L. A., \& Tellegen, A. (1988). Development and validation of brief measures of positive and negative affect: The PANAS scales. Journal of Personality and Social Psychology, 54(6), 1063-1070. https://doi.org/10.1037/00223514.54.6.1063

West, C. P., Huschka, M. M., Novotny P. J., Sloan, J. A., Kolars, J. C., Habermann, T. M., \& Shanafelt, T. D. (2006). Association of perceived medical errors with resident distress and empathy: A prospective longitudinal study. JAMA, 296(9), 1071-1078. https://doi.org/10.1001/jama.296.9.1071 